\title{
The co-evolution of our understanding of CD40 and inflammation
}

\author{
D. H. Wagner Jr \\ Published online: 10 April 2009 \\ (C) Springer-Verlag 2009
}

Keywords Adipocytes · CD40/CD40L · Inflammation . Lymphocytes · Obesity

\author{
Abbreviations \\ APC Antigen-presenting cell \\ DC Dendritic cell \\ Tregs Regulatory T cells
}

Numerous cell types and molecules influence inflammation. The ideal scenario would be the discovery of a biomarker 'master switch', affecting many of the control elements that drive the inflammatory process during pathologies. A master switch would extend our understanding of the disease process and provide an easy means of controlling inflammation. While such a master switch may not exist, growing experimental evidence suggests that CD40 plays a substantial, multi-faceted role in inflammation. This $45 \mathrm{kDa}$ type 1 membrane protein is a cell surface receptor that was originally discovered on the surface of B lymphocytes [1]. At this time it was described as inducing antibody class switching, a process that allows the body to produce the wide array of immunoglobulins necessary for immune protection and, in terms of autoimmunity, is necessary for the generation of autoantibodies. Autoantibodies are detected in numerous classical autoimmune diseases, including rheumatoid arthritis, systemic lupus erythematosus and type 1 diabetes. Indeed, the presence of more than one type of autoantibody can be, and often is, a decisive diagnostic component for each of these diseases. Mechanistically,

D. H. Wagner Jr $(\bowtie)$

University of Colorado Denver,

8th Floor, RC-1 North, C321, 12800 East 19th Avenue,

Aurora, CO 80045, USA

e-mail: David.Wagner@ucdenver.edu autoantibodies contribute to disease pathology, thus providing the first link between CD40 and disease pathology.

The role of CD40 in inflammatory processes is not confined to $\mathrm{B}$ cell function, with a greater degree of involvement implicated by the finding that other antigenpresenting cells (APCs), including macrophages and dendritic cells (DCs), express CD40 [2, 3]. APCs form part of the innate, rather than the adaptive, arm of the immune system, but, importantly, CD40 engagement on macrophages induces the production of pro-inflammatory cytokines, including TNF- $\alpha$, IL-6 [2] and IL-1 $\beta$ [4]. CD40 engagement on DCs results in 'licensing', which is needed for DC-T cell interactions. Specifically, CD40-licensing of DCs endows these cells with the ability to appropriately co-stimulate $\mathrm{CD}^{+}$and $\mathrm{CD} 8^{+} \mathrm{T}$ cells [5]. Consequently, blockade of the interaction between DCs and T cells inhibits $\mathrm{T}$ cell responses to viruses and other exogenous antigens [6].

A new insight into the part played by CD40 in inflammation was provided by the identification of a unique $\mathrm{T}$ cell subset that expresses CD40, referred to as Th40 cells [7-10]. These $\mathrm{CD} 40^{+} \mathrm{T}$ cells can give rise to pathogenic effector $\mathrm{T}$ cells [8-11], which are capable of altering receptor expression on peripheral $\mathrm{T}$ cells. This has significant implications for autoaggressive $\mathrm{T}$ cell generation, as the newly generated TCR molecules are not subject to central tolerance. In addition, CD40 is a highly effective co-stimulus for Th40 cells $[12,13]$. In fact, for pathogenic, autoaggressive Th40 cells, CD40 provides stronger co-stimulation than CD28, inducing the production of pro-inflammatory cytokines such as TNF- $\alpha$, interferon- $\gamma$ and IL-6 production [11-13].

In another twist, CD40 has proved to be far more ubiquitously expressed than was originally anticipated. Expression on endothelial cells, smooth muscle cells, astroglial and microglial cells has been documented [14], and now, in this issue of Diabetologia, Poggi et al. demonstrate another fascinating result-that CD40 is 
functionally expressed on adipocytes [15]. In addition, these authors demonstrate that CD40 engagement induces inflammatory cytokine production by the adipocytes. This result has significant implications for inflammation, including a role for cells other than immunocytes in this process, but also has broader reaching implications for different diseases. Pathologies that derive from inflammation are associated with autoimmune diseases, but non-autoimmune diseases are likewise affected by persistent inflammation. As Poggi et al. demonstrate, CD40 engagement affects glucose uptake and the production of leptin, a hormone responsible for weight management [15]. These newly identified consequences would have a direct effect on a diverse range of diseases that occur outside the realm of autoimmunity, such as type 2 diabetes and metabolic syndrome.

CD154, the ligand for CD40, is expressed on activated $\mathrm{T}$ cells and on platelets [16], and systemically elevated levels of CD154 are observed in both autoimmune and nonautoimmune diseases [17-21]. Furthermore, the soluble form of the protein (sCD154) exhibits cytokine-like properties [21]. In fact, $\mathrm{CD} 40$ and $\mathrm{CD} 154$ are members of the TNF- $\alpha$ receptor and TNF super-families, respectively [22]. Poggi et al. demonstrate that $\mathrm{T}$ cells expressing sCD154 or CD154 interact with adipocytes to induce the synthesis and secretion of cytokines such as TNF- $\alpha$ and IL6 [15]. This has direct implication potentially affecting the balance between regulatory $\mathrm{T}$ cells (Tregs) and pathogenic autoaggressive effector T cells, including Th40 cells. Tregs are generated in vitro by exposing naive T cells to TGF $\beta$ [23]; however, in the presence of IL-6, the Treg developmental pathway is switched in favour of the Th17 pathway [23]. Persistently high levels of IL-6, including that produced by fat tissue, could deplete the Treg pool by shunting cells into the Th17 pathway. Therefore, adipocytes producing IL-6 would affect the ratio of Treg to $\mathrm{T}$ effector cells. It is crucial that the homeostatic balance between Tregs and Th40 cells is maintained [24]. The discovery that CD40-induced signals occur independently of immunocytes highlights the fact that different physiological systems are intricately linked and therefore exert important effects on one another, potentially resulting in disease. In addition, these findings add to our understanding of the involvement of CD40 in disease processes. The fact that fat is not passive, but, rather, interacts with $\mathrm{T}$ cells, suggests how a vicious cycle leading to inflammation may be established in disease states as diverse as obesity, metabolic syndrome and type 2 diabetes.

The evolving role of CD40 in inflammation makes it a prime target for therapeutic intervention. However, such interventions are not without risk, as it is becoming apparent that numerous cell types express CD40 and that the physiological function of CD40 on each cell type results in unique outcomes. While in some cases CD40 signals may promote autoaggression, i.e. the development and expansion of autoantibodies and the generation of $\mathrm{T}$ cells that express self-antigen-reactive $\mathrm{T}$ cell receptors, preventing antibody class switching and hampering DC licensing, would have strongly negative effects. As shown by Poggi et al. [15], the role of CD40 in pathogenetic processes extends beyond autoimmune diseases, maybe to type 2 diabetes, metabolic syndrome and even obesity. Thus, a reasonable means of controlling CD40 signals portends an even greater outcome on an ever-growing number of diseases.

Duality of interest The author declares that there is no duality of interest associated with this manuscript.

\section{References}

1. Ledbetter JA, Shu G, Gallagher M, Clark EA (1987) Augmentation of normal and malignant $\mathrm{B}$ cell proliferation by monoclonal antibody to the B cell-specific antigen BP50 (CDW40). J Immunol 138:788-794

2. Alderson MR, Armitage RJ, Tough TW, Strockbine L, Fanslow WC, Spriggs MK (1993) CD40 expression by human monocytes: regulation by cytokines and activation of monocytes by the ligand for CD40. J Exp Med 178:669-674

3. Caux C, Massacrier C, Vanbervliet B et al (1994) Activation of human dendritic cells through CD40 cross-linking. J Exp Med 180:1263-1272

4. Wagner DH Jr, Stout RD, Suttles J (1994) Role of the CD40CD40Ligand interaction in $\mathrm{CD}^{+} \mathrm{T}$ cell contact-dependent activation of monocyte interleukin-1 synthesis. Eur J Immunol 24:3148-3154

5. Ridge JP, Di Rosa F, Matzinger P (1998) A conditioned dendritic cell can be a temporal bridge between a $\mathrm{CD}^{+} \mathrm{T}$-helper and a T-killer cell. Nature 393:474-478

6. Wekerle T, Kurtz J, Ito H et al (2000) Allogeneic bone marrow transplantation with co-stimulatory blockade induces macrochimerism and tolerance without cytoreductive host treatment. Nat Med 6:464-469

7. Wagner DH Jr, Newell E, Sanderson R, Freed JH, Newell MK (1999) Increased expression of CD40 on thymocytes and peripheral $\mathrm{T}$ cells in autoimmunity: a mechanism for acquiring changes in the peripheral T cell receptor repertoire. Int J Mol Med 4:231-242

8. Wagner DH Jr, Vaitaitis G, Sanderson R, Poulin M, Dobbs C, Haskins K (2002) Expression of CD40 identifies a unique pathogenic $\mathrm{T}$ cell population in type 1 diabetes. Proc Natl Acad Sci U S A 99:3782-3787

9. Vaitaitis GM, Poulin M, Sanderson RJ, Haskins KJ, Wagner DH Jr (2003) Cutting edge: CD40-induced expression of recombination activating gene (RAG) 1 and RAG2: a mechanism for the generation of autoaggressive $\mathrm{T}$ cells in the periphery. J Immunol 170:3455-3459

10. Waid DM, Vaitaitis GM, Wagner DH Jr (2004) Peripheral expansion of $\mathrm{CD} 4{ }^{\mathrm{lo}} \mathrm{CD} 40^{+}$auto-aggressive $\mathrm{T}$ Cells during insulin-dependent diabetes mellitus. Eur J Immunol 34:1488-1497

11. Waid DM, Wagner RJ, Putnam A et al (2007) A unique T cell subset described as CD4loCD40+ T cells (TCD40) in human type 1 diabetes. Clin Immunol 124:138-148

12. Baker RL, Wagner DH Jr, Haskins KJ (2008) CD40 on NOD CD4 $\mathrm{T}$ cells contributes to their activation and pathogenicity. J Autoimmun 31:385-392 
13. Munroe ME, Bishop GA (2007) A costimulatory function for T cell CD40. J Immunol 178:671-682

14. Suo Z, Wu M, Ameenuddin S et al (2002) Participation of protease-activated receptor- 1 in thrombin-induced microglial activation. J Neurochem 80:655-666

15. Poggi M, Jager J, Paulmyer-Lacroix O et al (2009)) The inflammatory receptor $C D 40$ is expressed on human adipocytes: contribution to crosstalk between lymphocytes and adipocytes. Diabetologia. doi:10.1007/s00125-009-1267-1

16. Sprague DL, Sowa JM, Elzey BD, Ratliff TL (2007) The role of platelet CD154 in the modulation in adaptive immunity. Immunol Res 39:185-193

17. Stumpf C, Lehner C, Eskafi S et al (2003) Enhanced levels of CD154 (CD40 ligand) on platelets in patients with chronic heart failure. Eur J Heart Fail 5:629-637

18. Tamura N, Kobayashi S, Kato K et al (2001) Soluble CD154 in rheumatoid arthritis: elevated plasma levels in cases with vasculitis. J Rheumatol 28:2583-2590

19. Aggarwal A, Schneider DJ, Sobel BE, Dauerman HL (2003) Comparison of inflammatory markers in patients with diabetes mellitus versus those without before and after coronary arterial stenting. Am J Cardiol 92:924-929

20. Tan J, Hua Q, Gao J, Fan ZX (2008) Clinical implications of elevated serum interleukin-6, soluble CD40 ligand, metalloproteinase-9, and tissue inhibitor of metalloproteinase- 1 in patients with acute ST-segment elevation myocardial infarction. Clin Cardiol 31:413418

21. Prahalad S, Martins TB, Tebo AE et al (2008) Elevated serum levels of soluble CD154 in children with juvenile idiopathic arthritis. Pediatr Rheumatol Online J 6:8

22. Gruss HJ (1996) Molecular, structural, and biological characteristics of the tumor necrosis factor ligand superfamily. Int J Clin Lab Res 26:143-159

23. Weaver CT, Harrington LE, Mangan PR, Gavrieli M, Murphy KM (2006) Th17: an effector CD4 T cell lineage with regulatory T cell ties. Immunity 24:677-688

24. Waid DM, Vaitaitis GM, Pennock ND, Wagner DH Jr (2008) Disruption of the homeostatic balance between autoaggressive $\left(\mathrm{CD} 4^{+} \mathrm{CD} 40^{+}\right)$and regulatory $\left(\mathrm{CD} 4^{+} \mathrm{CD} 25^{+} \mathrm{FoxP}^{+}\right) \mathrm{T}$ cells promotes diabetes. J Leukoc Biol 84:431-439 